\title{
A New Experiment to Engage M.Sc. Students in the Teaching/Learning Process
}

\author{
Maria João Martins $^{(1)}$, F. P. Maciel Barbosa ${ }^{(2)}$, C. Machado Ferreira ${ }^{(3)}$ \\ ${ }^{(1)} A M, D C T E$ \& INESC ID, Lisboa, Portugal \\ ${ }^{1}$ mariajoaomartinseist.utl.pt \\ ${ }^{(2)}$ Faculdade de Engenharia \& INESC TEC, Universidade do Porto, Portugal \\ ${ }^{2}$ fmb a fe.up.pt \\ ${ }^{(3)}$ IPC/ISEC \& INESC Coimbra, Portugal \\ ${ }^{3} \mathrm{cmacfer}$ isec.pt
}

\begin{abstract}
A new strategy was purposed and is being tested during this year, to increase students' participation and promote continuous learning and students' engagement in master's courses classes. With the implementation of the Bologna Process, the spectra of students has increased, which increases the difficulties faced by the lecturers since these students present different backgrounds and knowledge, thereby increasing the number of hours necessary to assure the completion of the programs. A description of a new approach design to increase students' participation, which is being tested in three different Universities and Polytechnic Institutes in Portugal is presented in this paper and some preliminary results are discussed.
\end{abstract}

Keywords - cooperative learning, distance interactive learning, internet applications, teaching and learning process.

\section{INTRODUCTION}

Following the implementation of the Bologna Process in Portugal, a two-tier system in Engineering courses still subsists, divided into Universities and Polytechnic Institutes. In Universities a five years course study program exists with an intermediate diploma (undergraduate diploma in Engineering Sciences, 180 ECTS) after the completion of the first three years of study. The completion of the five years (300 ECTS) confers a Master's degree in Engineering, recognized by the "Ordem dos Engenheiros", the professional body for Engineers. Universities award Master's and Doctoral degrees.

In Polytechnics a three + two years cycles of study exist, corresponding to the Bachelor, first cycle of studies ("Licenciatura" in Portuguese) and Master's degrees, second cycle of studies. The Polytechnics Bachelor degree is awarded after a period of study of 180 ECTS corresponding usually to six semesters and provides immediate access to a professional title. Normally, the Master's degree courses have a duration of four semesters that corresponds to 120 ECTS.

In order to apply for a second cycle of studies conferring a Master's degree, the candidates must hold a Bachelor's degree or legal equivalent. The two years Master's course can be lectured also in the Polytechnic Institutes or students can choose to move to a University to achieve a Master's program. Therefore, in Universities in recent Master's courses, a diversity of students is present. Besides the normal students pursuing a five years study program (three years
Bachelor + two years of Master's studies), other students are present coming from a three years Bachelor and also from other Universities with different backgrounds, presenting diverse capabilities, interests and basic knowledge depths. Trying to cater to the diverse needs of these students represents an additional challenge to the Professors, which are already facing difficulties, with the implementation of the Bologna process, namely with shorter semesters to deliver almost the same content as previously, while maintaining, or even increasing, the quality standards.

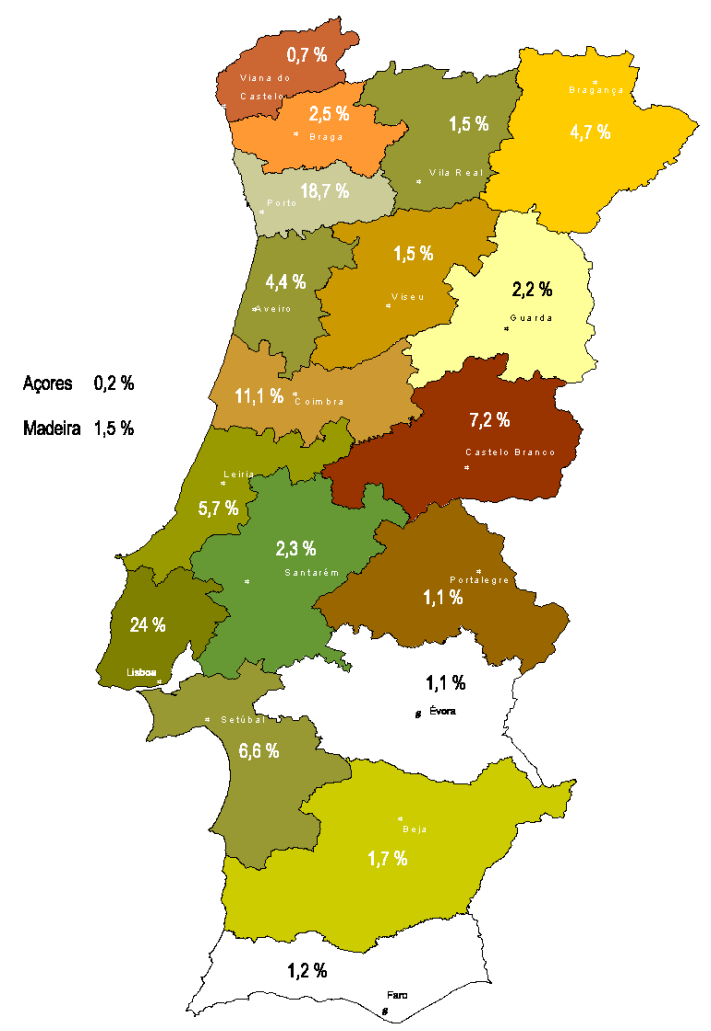

Fig. 1 Percentage of Electrical and Informatics Engineering Students at the different Universities and Polytechnic Institutes in Portugal

In order to accommodate all these requirements, increase students' participation and promote continuous learning and students' engagement, a new strategy was proposed and is 
being tested during this academic year. Since it is an exploratory project still going on, results will only be available in July/August 2013.

The principle of this new strategy is simple and relies on an application of the Tuning project to the teaching praxis. Its goal is to engage the students in the teaching/learning process, by promoting them from passive, sometimes uninterested spectators, to active members of a team, where they can perform a variety of roles. Figure 2 represents the Project's main strategy.
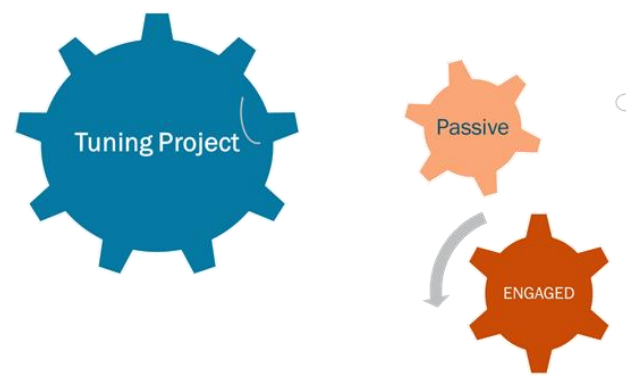

Fig. 2 Project's main strategy

High quality advanced technical education is essential to attract and to retain qualified students and also to produce well educated graduates who can contribute to the development of new generations of technology.

\section{STRATEGY DESCRIPTION}

In order to implement this strategy, a maximum dimension exists which is about 30-35 students. Engineering courses in Portugal can include up to 200 students each semester, so in order to implement the process, the course was divided in a number of classes and the course content is split between presential classes, either laboratory classes or problem solving classes, and web instruction modules. A schematic representation of the strategy is represented in figure 3 .

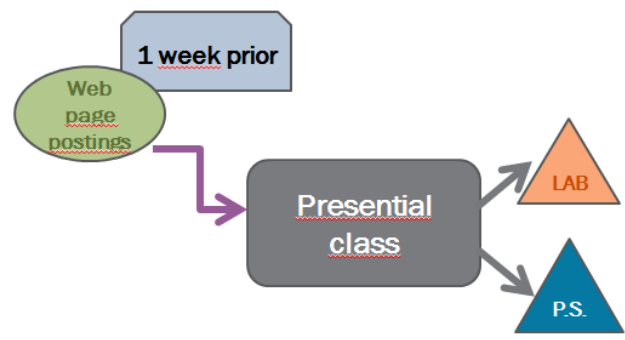

Fig. 3 Schematic representation of the Project's strategy implementation

A week before each class, a set of modules is posted in the discipline webpage, and must be solved prior to the class. These modules are short, but address essential points of the content of that class. In principle no student enrolled in that course can attend the class without submitting previously his/her answers to the modules' contents. The answers must be delivered, until 24 hours prior to the presential class.
The teacher collects the answers, reads them and gets an understanding of the problem areas, underlying the student's misconceptions and unsuccessful answers.

In the classroom these documents are used as a starting point to engage the class in an active search for surpassing the difficulties, by promoting discussions, team work and competition between the various groups of students. The students feel engaged in the classroom activities which can be adjusted by referring to specific points which have proven difficult for the majority of students.

Tutorial practices are an important part of this strategy, providing continuing support to the student. The difference in this project is that the tutor is not necessarily the teacher, but can also be a fellow student or a work team. Students have the opportunity to explore and create new ideas outside the classroom.

Although this project relies in web based assignments and communication, it is different from Distant Learning (DL) or Computer Based Training (CBT). The web is used primarily as a mean of communication, content organizer and probe to test students' conceptions or misconceptions. The teaching process takes place in presential classes, either laboratory classes or problem solving classes (PS), which are adjusted to fulfil the gaps in understanding, provided by the analysis of the assignments answers.

\section{PROJECT'S IMPLEMENTATION}

Each class was divided in groups of 2 to 3 students, which can also act as coaching teams for their peers. This division required a preparation and coordination of practical and theoretical benchmarks to be achieved in each session, in order to avoid differences in the extent of the subject covered with different tutors. It also requires experienced lecturers who can address all kinds of difficulties usually presented by the students. A database grouping FAQ's is under construction, which will prove a very useful tool for future semesters.

In order to compare results and get a global overview, at a national level, of the success of this approach, four classes were considered for this experiment: two at Lisbon, "Academia Militar (AM)", another one at Oporto University, "Faculdade de Engenharia (FEUP)", and a third one at Coimbra Polytechnic Institute, "Instituto Superior de Engenharia de Coimbra (ISEC)".

The subjects taught were also different, since the objective is to compare the methodology for different knowledge areas. In Lisbon it was applied to 3rd year students in the subjects of Applied Electromagnetics (12 students) and to 4th year students in the subject of Microwave Engineering in "Academia Militar" (8 students).

Applied Electromagnetics and Microwave engineering are an important discipline for transmission military officers, although they are also considered difficult subjects.

The main learning objectives of these courses include: in the Applied electromagnetics course an understanding of electrostatic fields, magnetostatic fields, the capacity to solve electric circuit problems, excited by DC or AC sources, and perform magnetic circuit analysis. In the microwave 
engineering course the learning outcomes include an understanding of microwave components and circuits, mode field theory and application of these devices in microwave communication systems.

In order to increase the attractiveness of these disciplines, new lab experiments were developed to show the relation of these techniques to measurement techniques. A simple apparatus allows the students to use reflectometry techniques to measure dielectric permittivity of several targets, such as plexiglass, wood, or other dielectric samples and compare the results with the theoretical calculations. A margin error acceptable for the measurement layout is defined in advance and students must justify the discrepancies found in the results.

Other experiments include the construction of simple antennas by using copper wire and their use in the reception of emitted fields, according to several emitting sources.

In figures 4 one of these lab experiments is shown.

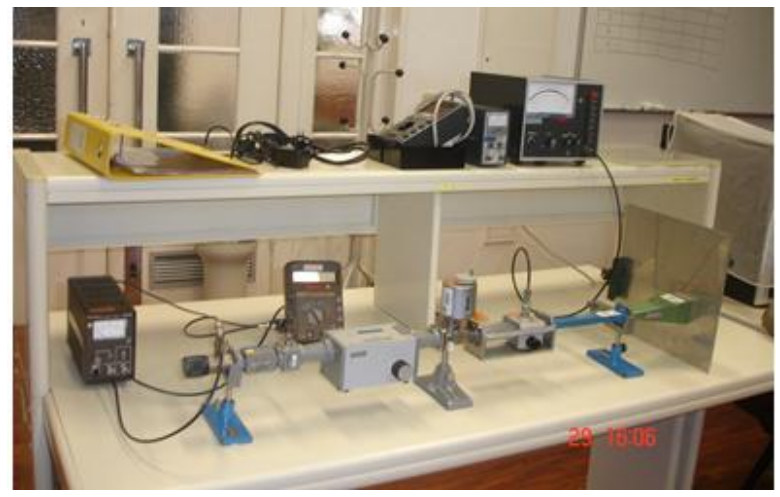

Fig. 4 Laboratory experiments in Microwave engineering courses

In Oporto, at the "Faculdade de Engenharia", the same methodology was used in the classes of Lighting and Industrial Installations (30 students), 5th year students. The importance of lighting designs, whether in offices or in industrial environments, must be appropriate to facilitate the development/implementation of all tasks and provide visual comfort. A lighting project usually requires highly complex calculations to determine the parametric values of light on points set on various model surfaces. The main learning objectives of the course unit include: to learn how to establish the electrical and lighting requirements for industrial installations and select design conditions, to learn about the requirements for inspection, testing and certification of electrical and lighting installations, to establish appropriate lighting criteria for efficient space and energy use as well as task performance, to conduct lighting evaluations and calculations.

At "Instituto Superior de Engenharia de Coimbra" the methodology was applied at Electric Power Systems Quality subject, a 3rd year, 2nd semester, with 40 students from the "Licenciatura" in Electrical Engineering, Power System specialization. Power quality has become one of the most important issues in the power industry and influences nearly all aspects of electrical engineering. The Electric Power
Systems Quality course was designed to provide knowledge of electric power quality for electrical engineer students and a practical overview of power quality issues, concerns and industry standards. The students will be able to monitor, access, analyze and solve common power quality problems. They also will acquire knowledge on the legal and regulatory power quality framework at national and international level. The course promotes active and collaborative learning that enables the students to develop the interpersonal skills and attitudes required in a world that is increasingly pluralistic and complex. These approaches facilitate and encourage learning as well as social interaction. The learning outcomes were assessed taking into account the marks achieved by the students.

Figure 5 shows the three institutions (FEUP, ISEC and $\mathrm{AM}$ ) involved in this experiment in Portugal and the number of students involved in each institution.

Simulators allowing the reproduction of lab experiments were developed and are being used as a means to introduce the students to lab experiments and increase their confidence with the available instrumentation.

So far, no statistical results were obtained since the semester will finish only by the end of June. From the qualitative point of view, a closer approach between students and lecturer was observed and the number of students engaged in a continuous evaluation scheme has increased. The approach was particularly effective in the lab classes, since it forced the students to prepare in advance for the laboratories, thereby increasing their ease with the lab instrumentation.

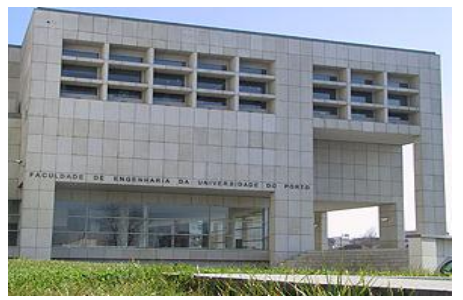

Faculdade de Engenharia, Universidade do Porto, FEUP, Porto, 30 students

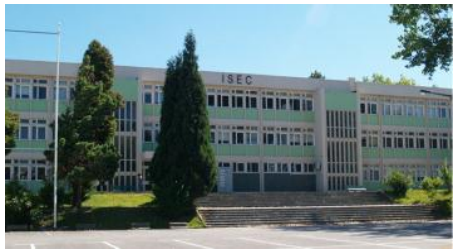

Instituto Politécnico de Coimbra/ Instituto Superior de Engenharia de Coimbra, IPC/ISEC, Coimbra, 40 students

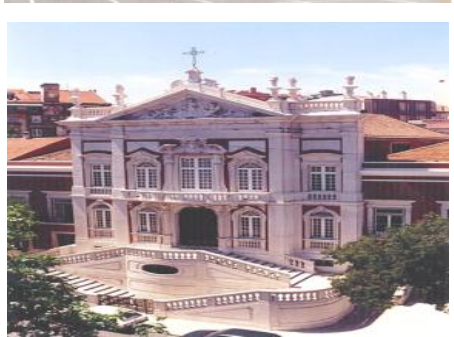

Academia Militar, AM, Lisboa, 20 students

Fig. 5 The two Universities and the Polytechnic Institute involved in this experiment in Portugal and the number of students involved in each institution 


\section{IV.CONCLUSIONS}

The results, so far, seem satisfactory. There is an active participation of students, which have come to realize that the additional effort required from them, pays back in the short/medium term, because they enter the classroom better prepared to understand the concepts, and can use the classroom time to engage in a discussion of their difficulties. One of the project aims is to develop the students' individual responsibility in the learning process.

This strategy has proven very effective in the labs classes. Labs play a central part in an advanced technical education and are a fundamental element of the educational process. The previous preparation of the labs practical work has increased students' easiness with the equipment, a better understanding of the goals to be fulfilled at the end of each session. This allows the labs' sessions to be shortened in duration since the time is used with more effectiveness. It is expected that the students will benefit from this experience of actually working as members of a team in relation to learning in conventional classes.

\section{ACKNOWLEDGMENT}

The authors wish to acknowledge, The European Commission through the SALEIE project (Strategic Alignment of Electrical and Information Engineering in European Higher Education Institutions) for grants and support.

\section{REFERENCES}

[1] Knol, G., "How to Build Articulate UML Class Models", [Online] Available:http://uml.org/HTB_Articulate_Class_Models_OMG.pd, 2008 Accessed 2nd May 2013.

[2] Kolb, David A., "Experiential Learning: Experience as the Source of Learning and Development", Prentice Hall, Inc., A Division of Pearson Education, Upper Saddle River, New Jersey, 1984. [Online] Available: http://www.businessballs.com/kolblearningstyles.htm, Accessed 2nd May 2013.

[3] LSTC, IEEE Learning Technology Standards Committee Website, 2007. [Online] Available: http://www.ieeeltsc.org:8080/Plone, Accessed 2nd May 2013.

[4] C. Meyers, T. B. Jones, "Promoting Active Learning: Strategies for the College Classroom”, ISBN: 978-1-55542-524-1, May, 1993.

[5] Maria João Martins, C. Machado Ferreira and F. Maciel Barbosa, "The Bologna Process Implementation in EEI Engineering in Portugal", European Association for Education in Electrical and Information Engineering Conference, Maribor, Slovenia, $13^{\text {th }}-14^{\text {th }}$ June, 2011.

[6] M. M. Travassos Valdez, C. M. M Ferreira and F. P. Maciel Barbosa "Software Packages to Support Electrical Engineering Virtual Lab". International Journal on Emerging Technologies in Learning, iJOE2012. ISSN: 1861-2121, Volume 8, Special Issue 2: exp.at'11, 2012, pp. 19-23, Special Focus Papers.

[7] M. M. Travassos Valdez, C. M. M Ferreira and F. P. Maciel Barbosa "Desktop Vr Systems - A Distance Learning Method and Technology". IEEE EDUCON 2013, Special Track "IT and Engineering Pedagogy" (ITEP'13), Berlin, Germany, 2013.

[8] M. M. Travassos Valdez, "Novas Metodologias no Ensino e Aprendizagem na Área da Engenharia Eletrotécnica", Ph.D. Thesis Faculdade de Engenharia, Universidade do Porto, FEUP, 2013 (in Portuguese).

[9] D. Ary, L. C. Jacobs, and C.Sorensen, "Introduction to research in education", (8th ed.), Belmont, CA: Wardsworth, 2010

[10]R.M. Felder and R. Brent, "Cooperative Learning in Technical Courses: Procedures, Pitfalls, and Payoffs". ERIC Document Reproduction Service, ED 377038, 1994. 